\title{
The Role of Incubators in the European New Space Economy
}

Marc Abi-Fadel and Walter A.R. Peeters

Space Business and Management, International Space University, IIIkirch-Graffenstaden, France.

\begin{abstract}
Incubators have since long been an important element in the innovation cycle. In the framework of the new space economy, the role of incubators has changed over the past decade with a larger overlap between incubator and accelerator functions. Whereas this transition took earlier place in United States, the same trend is now also obvious in Europe. This article attempts to describe the present situation in Europe, at the same time clarifying the different types of incubators. As a basis of this article, European studies on incubators are described and analyzed. In a second step, a comparison is made between European and more result-oriented U.S. publications on the performance of incubators. To validate a potential need, a survey was made on the desire to establish such new space-oriented incubator in the environment of the International Space University at its central campus in France. The results of this survey are reported in this article.
\end{abstract}

Keywords: business incubators in Europe, new space economy, business plan generation, International Space University

\section{INTRODUCTION}

W hen public financing for space projects started to decrease, space companies were forced to diversify and create new products in response to market demand, in contrast to previous government-oriented space markets. ${ }^{1}$ To do this, they used their own financial reserves or applied for debt financing, in both cases mainly using own funding. As described in a previous article, ${ }^{2}$ a new generation of space companies came into existence whereby mainly young entrepreneurs concentrated on maximizing the use of existing infrastructures and space data to create new niche markets, as shown in Figure 1. This was the start of the new space economy.

Because a major distinction between commercial space applications and these new applications is the root source of funding, a definition of new space entrepreneurial activi- ties has been proposed, where "Private Companies which act independent of governmental space policies and funding, targeting equity funding and promoting affordable access to space and novel space applications." 2

Although authors have correctly discussed the validity of the term "commercial" in the context of space companies, ${ }^{3}$ many new space companies have made themselves more independent from government space contracts and can, therefore, be labeled as fully commercially oriented. The question can be asked why vested space companies are not entering this market environment, instead leaving a place for new companies to develop. A number of factors play a role in this process. Many new space companies develop applications with low capital investments and use existing, mainly free, space data combined with algorithms for specific applications, whereas vested companies are often more interested in hardware production. New space companies also use smallsats* produced at very low cost. In general, large companies with high overhead structures are less interested in such production (exceptions are the large serial productions, such as OneWeb, producing up to 2 smallsats per day, which raised commercial interests from Airbus ${ }^{4}$ ). As a result of this new wave, the number of new space startups is growing exponentially, as reported in a recent study. ${ }^{5}$ Indeed, whereas the number of new space companies established was in the order of 10 yearly around 2002, this has grown to $\sim 40$ yearly in 2014 reaching at present some 80 newly established companies per year according to the authors of this study.

Key elements of these new companies are the independence of goals as well as the access to private capital markets as they neither have access to existing company funds nor, in general, collateral for debt financing. As a reaction from the financing community, it is possible to see the recent increase in seed capital funding as well as venture capital availability (next to debt financing, which, however, requires collateral and is, therefore, more linked to new endeavors of existing companies) (Fig. 2). ${ }^{6}$

*The definition of smallsats differs from organization to organization. In this context the NASA definition of smaller satellites, up to $180 \mathrm{~kg}$ and of limited size, seems most appropriate. 


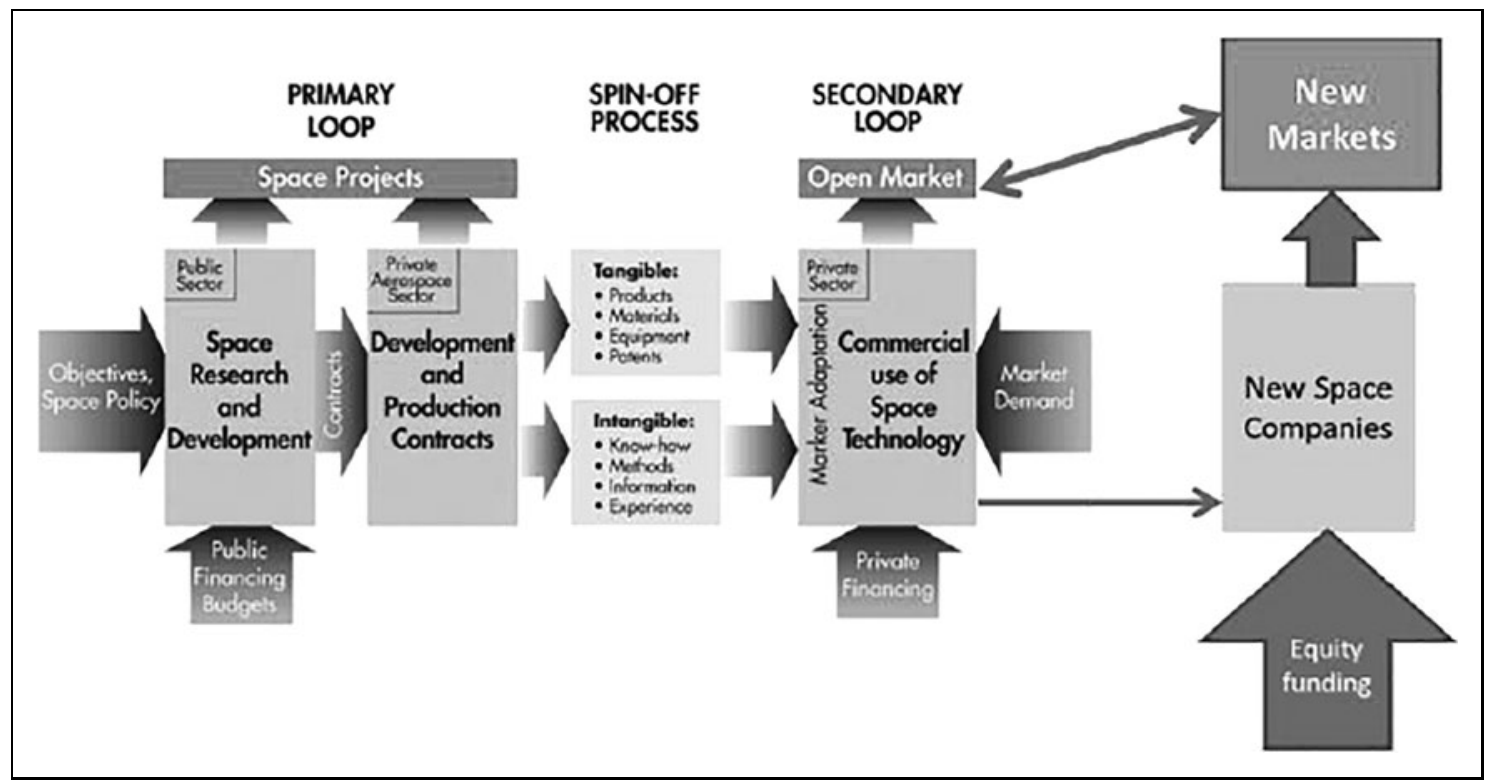

Fig. 1. Distinction between commercial space and new space activities ${ }^{1}$.

Compared with a similar situation a few years ago, ${ }^{7}$ we can now see that venture capitalists are concluding less deals, but are prepared to invest much larger amounts from the start of financing onward. ${ }^{\dagger}$ In addition to this, business angels are now more grouped into so-called Business Angel Networks (BANs), and are open to lower entry amounts. The report ${ }^{6}$ indicates BAN equity investments presently in the range of $50 \mathrm{~K} \$-1 \mathrm{M} \$$, venture capitalist funding in the range of $2 \mathrm{M} \$-75 \mathrm{M} \$$, whereas private equity funds restrict themselves to larger investments in the range of $100 \mathrm{M} \$-1 \mathrm{~B} \$$ and more.

With these amounts in mind, it is evident that there is a need for young entrepreneurs to propose a solid business plan. Here the early incubation function plays a paramount role by providing startup companies with accommodation and seed funding in the order of $50 \mathrm{~K}$ to $200 \mathrm{~K} \$$ in Europe, complemented with important advice and coaching to prepare a robust and coherent business plan.

\section{THE ROLE OF INCUBATORS IN THE NEW SPACE ECONOMY IN EUROPE}

Based upon comparison of different models, a typical activity flow for startups in Europe is summarized in Figure $3 .^{8} \mathrm{~A}$ typical activity flow of startups begins with the ideation process to the creation of a fully established company. First, entrepreneurs must generate ideas and perform market re-

${ }^{\dagger}$ A previous evaluation performed in $2009^{7}$ showed an average venture capital funding in the range of $0.1-5 \mathrm{M} €$. search. These steps 1 and 2 are usually performed by the entrepreneurs themselves, but their efforts can be complemented through workshops and advice provided by technology business incubators (TBIs).

TBIs typically focus on supporting young entrepreneurs starting at step 3 (building a team) and offering services all the way to step 7 (first founding rounds). Depending on the business model of TBIs, they can choose to primarily focus on providing services typically offered by incubators (steps 3-7) or services offered by boosters/accelerators (steps 8-10). TBIs can choose to adopt such hybrid models where they provide services across the entire support flow, merging incubation and acceleration services, or limit themselves to the incubation phase.

Pauwels et al. ${ }^{9}$ identified and defined 5 key design elements and constructs of TBIs in Europe, which were synthesized through careful analysis of 13 case studies spread across the United Kingdom, Germany, and France. These elements and constructs touch upon the business and operational models of incubators and accelerators as illustrated in Figure 4.

While designing a TBI, the services offered must be agreed upon, including its strategic focus, target sector, and regional coverage, the TBI can choose to offer access to experienced entrepreneurs as mentors, provide business training courses and counseling services that act as business assistance for the entrepreneur, and monitoring tools for TBI management.

As access to funding is one of the major hurdles for young entrepreneurs, TBIs focus on leveraging private investors, corporate funds, and public funds. Alternative revenue streams can help the TBI maintain decent financial statements. 


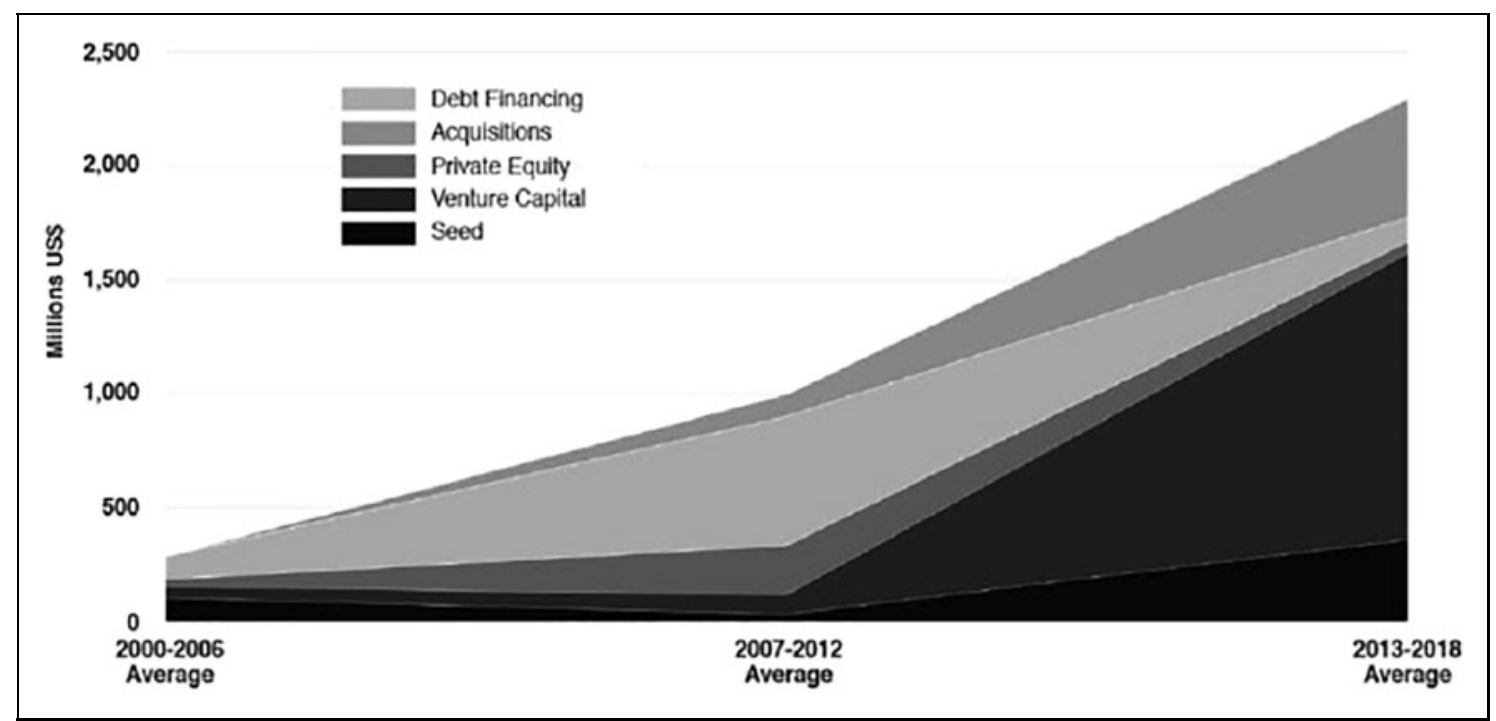

Fig. 2. Evolution of space financing sources (Source: Bryce ${ }^{6}$ ).

Depending on the aims and objectives of the TBIs, Pauwels et $a l^{9}{ }^{9}$ have identified 3 categories of TBIs in Europe that leverage the aforementioned design elements in distinct ways. The first category, ecosystem builders, focuses on building a corporate ecosystem: generating startups to be acquired by large corporations that benefit from lower development costs and a premium talent stream. The second category, deal-flow makers, in contrast, is powered by pri- vate investors looking to increase their wealth by investing in promising startups with some proven track record, thus minimizing the risk of failure. Lastly, welfare stimulators are publicly supported TBIs that provide an extensive curriculum and support very early stage ventures.

Researchers ${ }^{10}$ have studied the operation of incubators and have noted that their role has evolved over time. They identified 3 waves over the past few decades, with the authors of

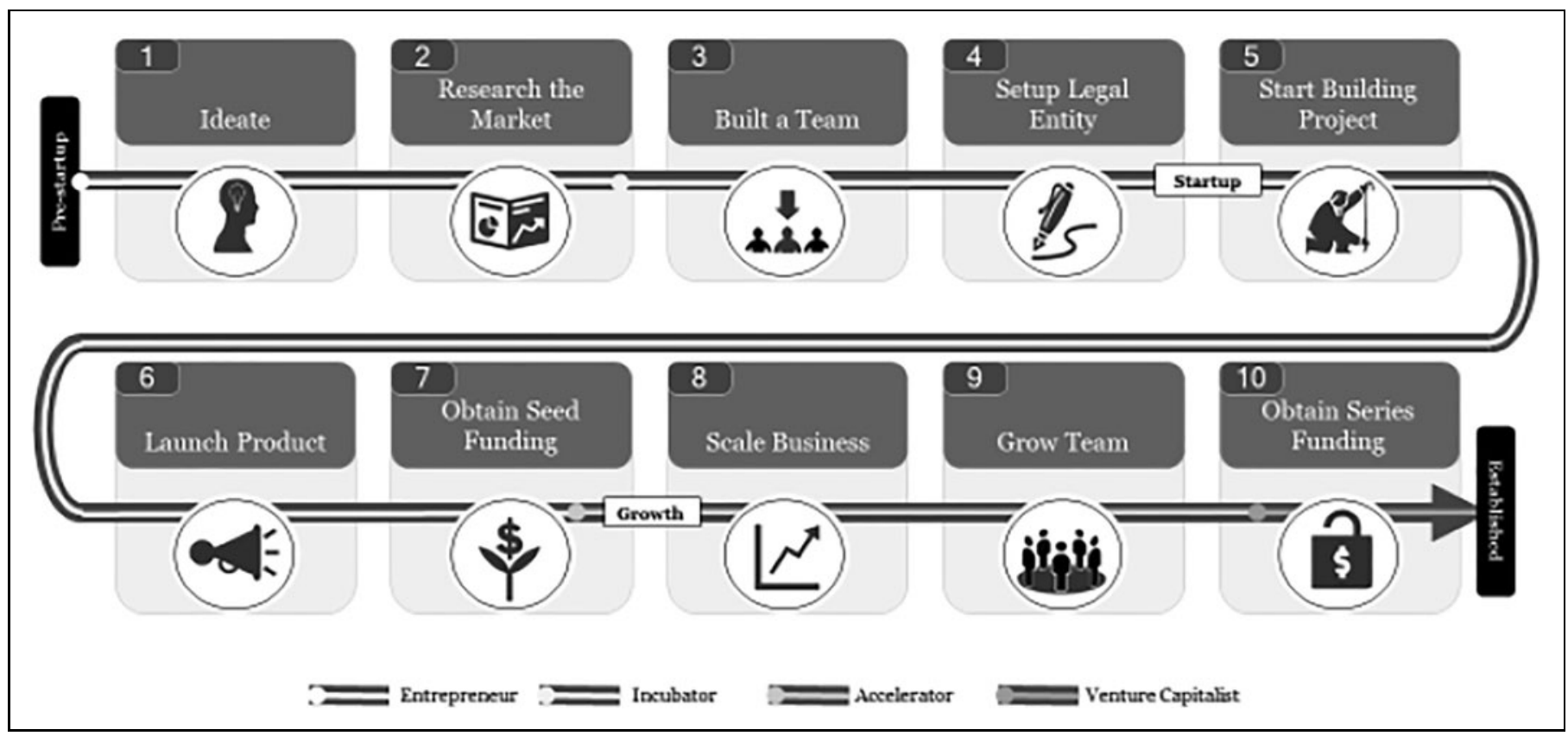

Fig. 3. Typical activity flow of startups investment ranges (Abi-Fadel ${ }^{8}$ ). 


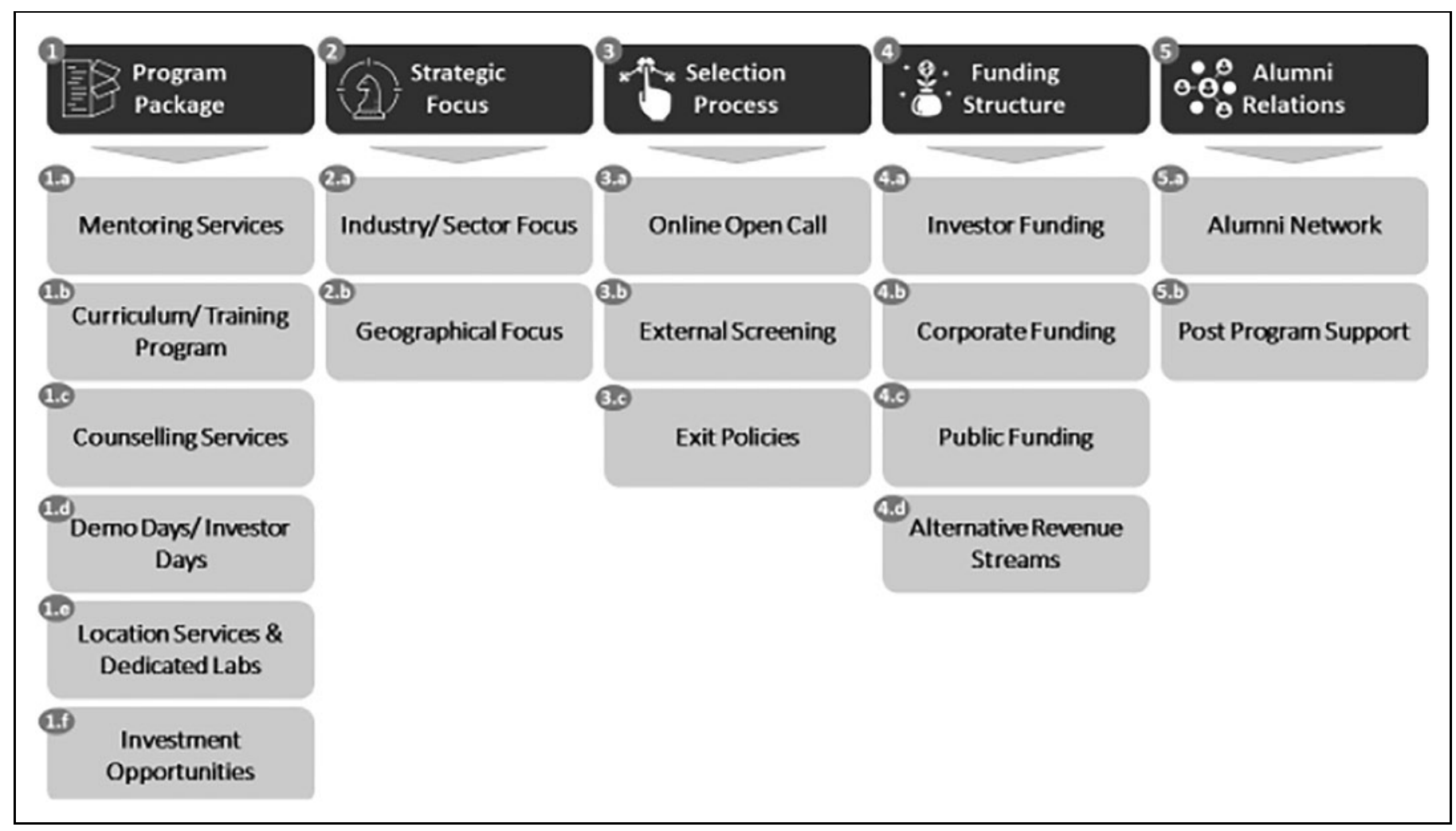

Fig. 4. Incubator design elements (adapted from Pauwels et al. ${ }^{9}$ ).

this article coming to the conclusion that a recent new wave is appearing that has been added to Figure. 5. Indeed, recently we have witnessed a blurring line of demarcation between the different TBI models. Incubators, accelerators, and coworking spaces are more and more merging, offering tailored services to their tenants. An interesting evolution is the creation of a direct link between incubators and accelerators, where a tenant is first within the incubator and then directly links to an accelerator or booster program, thus extending the support flow.

\section{SUCCESS OF INCUBATORS: BENCHMARKING WITH U.S. MODELS}

The question remains whether new incubator models have efficiently contributed to the creation of young enterprises in

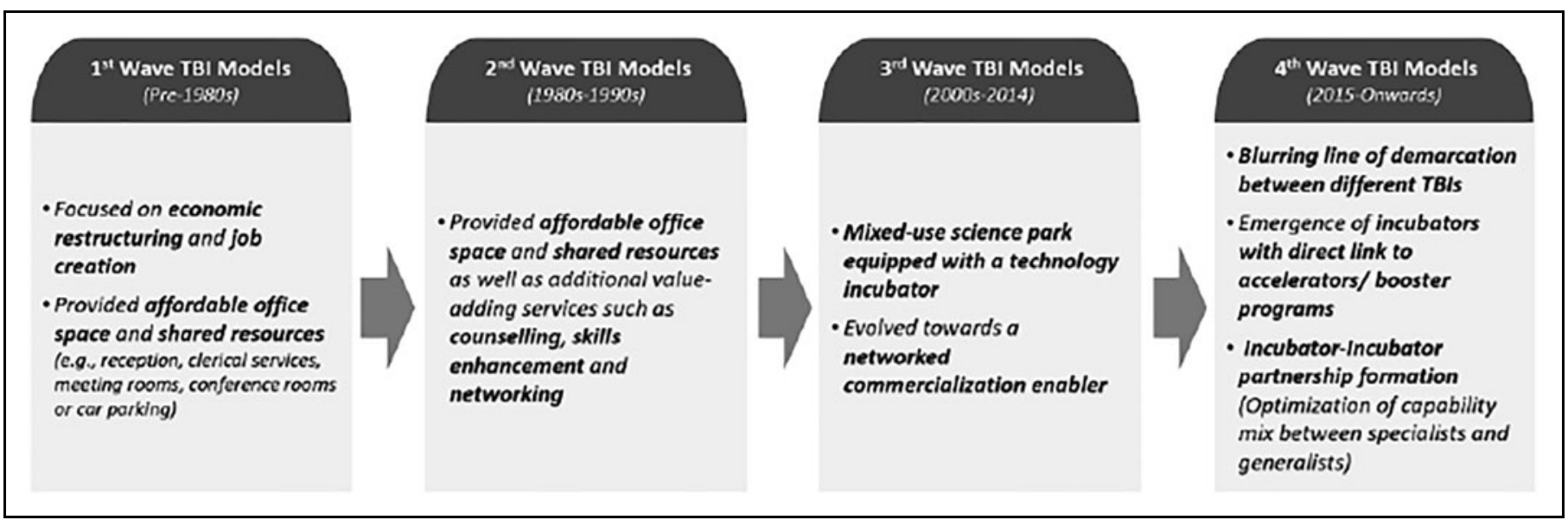

Fig. 5. Evolution of technology business incubators (adapted from Mian et al. ${ }^{10}$ and extended by the authors). 


\section{THE ROLE OF INCUBATORS IN THE NEW SPACE ECONOMY}

the new space economy. As the recent models are relatively new in Europe and in view of the time needed to measure the success of a startup, it is hard to assess the European ecosystem. In contrast, as with many aspects of the new space economy, the situation is much more advanced in the United States.

The first public incubator in Philadelphia is mentioned by Campbell and Allen ${ }^{11}$ as early as 1964. Campbell defined incubators as ${ }^{12}$ real estate projects with shared space and administrative arrangements [and] organize the business development process. The concept coincided in broad terms with the first wave as described in Figure 5. Other authors ${ }^{10}$ situate pioneering efforts of business incubators at Stanford University in 1951, followed by the Industrial Center of Batavia in New York, in 1959. Varying definitions of the term incubator lead to these different opinions.

An interesting benchmark is that scholars estimate at present the number of incubators at 4-5 per million people in the United States and United Kingdom against 1-2 per million people in the rest of the world, ${ }^{\ddagger}$ clearly showing the more advanced stage of the concept in these 2 countries.

Olson ${ }^{13}$ points out a considerable difference in approach, and labels the U.S. model as "Darwinian." The U.S. concept is geared toward rapidly pushing startups to prove business viability. This is based on a competitive selection process with limited seed funding (requiring a greater initial level of self-funding) for short periods of 3-6 months. After this time, incubators link startups to the networks of equity investors, such as business angels or venture capitalists. The best known U.S. incubator working this principle is Y-Combinator, ${ }^{\S}$ established in 2005 in Cambridge, MA, who request a 5\%-7\% equity stake for their support.

A study published in $2011,{ }^{14}$ based upon an analysis of 19,000 incubated businesses, came to the conclusion that business incubation increased the growth rate considerably in the order of $130 \%$, in terms of employment and sales growth. An interesting additional finding was that femaleowned incubators had 38\% less risk to fail than male-owned incubators.

The aforementioned confusion between the different types of incubators (and accelerators) and the absence of key performance indicators is a recent and frequent topic to align and compare various performance studies in the United States. The U.S. administration has, therefore, launched a study to propose more standardized performance measure-

*https://www.quora.com/How-many-business-incubators-are-there-in-the-world §https://www.ycombinator.com/ ments for business incubators. ${ }^{15}$ However, a general consensus on this complicated question has not been reached to date. $^{10}$

The issue is even more complicated if incubator performances are compared between the United States and emerging space countries. As examples, we can refer to an excellent comparison with the incubators in developing space powers such a China and India, ${ }^{16}$ but also between incubators in the United States and the Gulf Cooperation Council States. The lack of universally agreed-upon key performance indicators makes such comparisons quasi-impossible. ${ }^{17}$ Two main differences that have been observed are worth mentioning. First, emerging space countries are focusing more on establishing new space ecosystems, where incubatees* are provided with government grants under certain conditions, but, in general, do not have to be reimbursed afterward. In contrast, although generally accepted in the Western entrepreneurial economy, sharing of equity is less traditional in the case of emerging space nations. ${ }^{17}$

Bridging to the next chapter, it is interesting to consult a recent research article analyzing the European incubator landscape in comparison with the U.S. situation. On the basis of comparative research, van Weele et al. ${ }^{18}$ compare the U.S. and European incubator landscape, and find the main issues in Europe are a lack of market orientation, with a too high interest in technical features but insufficient knowledge of the target market. In addition to this, a lacking entrepreneurial spirit and a risk-averse attitude from European young entrepreneurs are mentioned as another barrier. The fact that in general European Universities do not focus sufficiently on entrepreneurship is considered by the authors as an additional barrier to encourage startup activities, in contrast to the more advanced programs available in the United States.

\section{CASE STUDY: THE INTERNATIONAL SPACE UNIVERSITY INCUBATOR}

The International Space University (ISU) ${ }^{19}$ attracts space enthusiasts with vastly different backgrounds as participants. Scientists, engineers, lawyers, and economists work together on common projects during their participation in ISU programs, hence it is no surprise that ideas are generated in these unique combinations that have led to the creation of several space startups in recent years.

This process has been enhanced by the introduction of entrepreneurial oriented courses and workshops in the ISU

"Also called "tenants," referring to an entrepreneur located within the premises of an incubator. 
programs, whereby the students, with the help of experienced alumni working in the space financing sector or being entrepreneurs themselves, receive coaching on how to prepare and present a business plan.

In turn, this has generated the idea to allow alumni to further develop their projects in-house by means of an ISU incubator. Indeed, many successful ideas over previous years have not come to fruition due to the lack of this resource. One of the main reasons for this interest is the many space experts who participate yearly in ISU activities, covering a broad field of expertise in line with the interdisciplinary vocation of ISU. ${ }^{20}$ As such, ISU located startups may benefit of this presence for advice and even contacts with potential business partners. To validate the need for an ISU incubator, a questionnaire was developed and sent to recent alumni with the result that $>60 \%$ of the respondents confirmed that they had a startup idea studying at ISU and $>67 \%$ of the ISU alumni responded that they would have had interest to join an ISU incubator if this would have been available. ${ }^{8}$

As a result of this survey, ${ }^{8}$ potential incubatees expressed the need for mentoring services from ISU-experienced alumni and dedicated training programs within the ISU curriculum. In addition, a counseling service to support the teams with managerial solutions was considered as an asset. As far as funding is concerned, contact with potential investors and access to first investment rounds (as a result of agreements with, e.g., local investment funds and ESA-BIC funding) were considered equally important.

\section{CONCLUSION}

Incubators play a paramount role in the present new space economy. The ideas generated by space entrepreneurs can lead to increasingly viable niche markets, which can be profitable for small and medium enterprises (SMEs) but may not be attractive enough to be incorporated in large space companies.

In cases of combining space data with algorithms, there is limited need for laboratory space or workshops. TBIs are important for startups when preparing a business plan for investors, hence the need to have access to coaching and counseling as well as support to obtain first financing rounds of seed capital before approaching major investors.

Incubators initially only provided equipped working space; however, modern incubators now provide additional coaching support, a link to partner accelerators, plus early financing sources.

An outstanding issue is the performance measurement of incubators, in particular when comparing such performances in different countries with different business cultures. Therefore, as a benchmark, results from U.S. experience are re- flected in this article in comparison with the present incubator status in Europe.

Owing to its interdisciplinary character, the ISU brings participants with different backgrounds and cultures together. The ISU curriculum has been specifically adapted to reflect the request to provide more entrepreneurship-oriented content, and provides more emphasis on entrepreneurial skills and workshops.

A logical extension of this trend is to provide incubator possibilities within ISU to alumni. To validate this, a questionnaire was sent to recent alumni whereby $\sim 67 \%$ applauded this initiative.

\section{ACKNOWLEDGMENT}

The authors thank Evon Koprowski for her support.

\section{AUTHOR DISCLOSURE STATEMENT}

No competing financial interests exist.

\section{FUNDING INFORMATION}

The authors thank the Eurometropole of Strasbourg for providing their support to this project.

\section{REFERENCES}

1. Peeters W. Is new space lifting off? Prospective Stratégique 2016;45:60-65.

2. Peeters $W$. Towards a definition of New Space? The entrepreneurial perspective. New Space 2018;6(3):187-190.

3. Davidian K. Do "commercial" space companies exist? New Space. 2016;4(4): 269-285.

4. Space Daily, OneWeb starts to mass-produce satellites in Florida. 2019. www.spacedaily.com/reports/

OneWeb_starts_to_mass_produce_satellites_in_Florida_999.html (Last accessed on June 13, 2019).

5. NSR. Emerging Space Market Analysis, 2nd Edition. Cambridge, MA: NSR, 2019.

6. Bryce, Start-up Space. 2019. https://brycetech.com/reports.html (Last accessed on June 19, 2019).

7. ISU, Financespace, (ISU Study, ISU, Strasbourg, 2007). https://cordis.europa.eu/ project/rcn/78591/factsheet/fr (Last accessed on November 28, 2019).

8. Abi-Fadel M. ISU Business Incubator. Need Assessment and Business Model Development. Final Project Report MSS2019. Strasbourg: ISU, 2019.

9. Pauwels $C$, Clarysse $B$, Wright $M$, Van Hove J. Understanding a new generation incubation model: The accelerator. Technovation 2016;50-51(2010):13-24.

10. Mian S, Lamine W, Fayolle A. 2016. Technology Business Incubation: An overview of the state of knowledge. Technovation 50-51, pp. 1-12. [online]. http://dx.doi.org/10.1016/j.technovation.2016.02.005. (Last accessed on June $25,2019)$.

11. Campbell C, Allen DN. The small business incubator industry: Micro-level economic development. Econ Dev 0 1987;1(2):178-191.

12. Campbell C, Kendrick RC, Samuelson DS. Stalking the latent entrepreneur: Business incubators and economic development. Eco Dev Rev 1985;3(2):43-48.

13. Olson T. But will it blend? An overview of the relative ability of incubators and accelerators to nurture and fund space-related startup enterprises. Presented at IAC, IAC-16. E6.2.5.x32773, IAC, Guadalajara, Mexico, 2016.

14. Amezcua A. Boon or boondoggle? Business incubation as entrepreneurship policy. PhD thesis (Syracuse University, 2010). 
THE ROLE OF INCUBATORS IN THE NEW SPACE ECONOMY

15. Cheng $S$, Schaeffer P. Evaluating without bias: A methodological perspective on performance measures for business incubators. Research Note 2011 https://core.ac.uk/download/pdf/6342229.pdf. (Last accessed on June 26, 2019).

16. Tang M, Baskaran A, Pancholi J, Lu Y. Technology business incubators in China and India: A comparative analysis. J Global Inf Technol Manage 2013;16(2):33-58.

17. Al-Mubaraki HM, Busler M. Challenges and opportunities of innovation and incubators as a tool for knowledge-based economy. J Innovation Entrepreneurship 2017;6(15)

18. van Weele $M$, van Rijnsoever $F$, Eveleens $C$, Steinz $H$, van Stijn N, Groen $M$. Start-EU-up! Lessons from international incubation practices to address the challenges faced by Western European startups. J Technol Transfer 2019;43: 1161-1189.

19. ISU. www.isunet.edu. (Last accessed on June 19, 2019).
20. Bukley A, Clement G, Peeters W, Welch C. A Quarter-Century of '3IS' Space Education-25 Years of the International Space University, IAC-12-E1.8.3, 63rd International Astronautical Congress, 1-5 October 2012, Naples, Italy.

Address correspondence to: Walter A.R. Peeters Professor, Space Business and Management International Space University Illkirch-Graffenstaden F67400

France

E-mail: peeters@isunet.edu 